\title{
Variação de peso no pós-parto de vacas F1 Holandês x Zebu de diferentes ordens de parto*
}

\section{Weight variation in post calving F1 Holstein $x$ Zebu cows of different calving orders}

\author{
José Reinaldo Mendes Ruas, ${ }^{* *},{ }^{* * *}$ Edilane Aparecida da Silva, ${ }^{* *},{ }^{* * *}$ Domingos Sávio Queiroz, ${ }^{* *},{ }^{* * *}$ \\ José Afonso Gonçalves Soares Júnior, ${ }^{* * *},{ }^{* *}$ Marcos Eduardo Gonçalves Pereira, ${ }^{* * * *}$ \\ Gustavo Chamon de Castro Menezes, ${ }^{* \star * * *}$ Vicente Ribeiro Rocha Júnior, ${ }^{* * * * *},{ }^{, * * * * *}$ Maria Dulcinéia da Costa ${ }^{* * * * * * *}$
}

\begin{abstract}
Resumo
Utilizou-se do teste de regressão para estudar a variação do peso após o parto de vacas F1 Holandês x Gir, Holandês $x$ Guzerá, Holandês $x$ Azebuado e Holandês x Nelore em nove ordens de partos. Os pesos utilizados foram o peso ao parto e a cada 28 dias até o próximo parto. Os animais F1 Holandês $x$ Zebu apresentaram diferentes comportamentos da variação de peso entre as ordens de partos e grupos genéticos. Na primeira ordem de parto não houve variação de peso para os grupos genéticos Holandês x Guzerá, Holandês x Azebuado e Holandês x Nelore, mas para o grupo genético Holandês x Gir ocorreu redução de peso na fase inicial e ganho a partir do meio até o final da lactação. Da segunda até a sétima ordem de parto, foram observadas variações no ganho de peso; de uma forma geral, todas ganharam peso após o parto. Já na oitava e nona ordens todas as vacas, independentemente do grupo genético, mantiveram o peso após o parto. Parte deste comportamento pode ser atribuído ao não ajuste da dieta à produção de leite destes genótipos, o que indica diferenças nas exigências nutricionais dos animais F1 Holandês x Zebu em relação aos animais especializados.
\end{abstract}

Palavras-chave: grupo genético, ordem de parto, peso corporal.

\begin{abstract}
It was used regression test to study the weight variation after calving of cows F1 Holstein $x$ Gyr, Holstein $x$ Guzerat, Holstein $x$ "Azebuado" and Holstein $x$ Nellore in nine orders of calving. The weights used were weight at calving and every 28 days until the next calving. The F1 Holstein $x$ Zebu animals showed different behaviors of the weight variation between calving orders and genetic groups. In the first calving order there was not weight variation for genetic groups Holstein x Guzerat, Holstein x "Azebuado" and Holstein $x$ Nellore, but for the Holstein $\times$ Gyr genetic group occurred weight reduction in the initial phase and gain from the middle until the end lactation. From second until seventh order of calving, variations in weight gain were observed, in general all gained weight after calving. Already in the eighth and ninth order all cows, regardless of genetic group maintained weight after calving. Part of this behavior can be attributed to not adjust the diet to milk production of these genotypes, which indicates differences in nutritional requirements of animals F1 Holstein $x$ Zebu in relation to specialized animals.
\end{abstract}

Keywords: genetic group, calving order, weight.

\section{Introdução}

A variação de peso em gado leiteiro é devido à associação genética entre o peso corporal, escore de condição corporal e parâmetros de mobilização de tecidos (Rennó et al., 2006). O balanço torna-se negativo quando as demandas do animal ultrapassam a ingestão de nutrientes, ocorrendo aumento na taxa de lipólise e redução na de lipogênese, devido à utilização das reservas corporais (Butler, 2008).
Essa variação pode alterar a intensidade por causa da interação de fatores: a capacidade de mobilização de reservas corporais no início da lactação, a exigência energética para produção, a disponibilidade de alimento e grupo genético.

Em gado mestiço há menor mobilização das reservas corporais no início da lactação, refletindo em balanço energético negativo de menor duração e intensidade, se comparado com os dados na literatura para raças especializadas (Carvalho et al., 2009).

*Recebido em 23 de março de 2013 e aceito em 15 de janeiro de 2014.

**Pesquisador Epamig - Empresa de Pesquisa Agropecuária de Minas Gerais,

****Zootecnistas autônomo.

*****Doutorando Programa de Pós-Graduação Zootecnia - DZO-UFV.

******Professor Unimontes - Janaúba-MG.

*******Bolsista CNPq.

Autor para correspondência: e-mail: jrmruas@epamig.br 
Vacas mestiças apresentam comportamento diferente se comparado a vacas especializadas para exigência nutricional e aproveitamento da dieta. O estudo do comportamento da variação de peso pode servir para melhor compreensão das particularidades do gado mestiço facilitando o ajuste nutricional.

Portanto, objetivou-se caracterizar a variação do peso de vacas lactantes F1 Holandês $x$ Zebu proveniente do cruzamento de diferentes bases maternas zebuínas com touro Holandês.

\section{Material e métodos}

Foram utilizados dados de fêmeas cruzadas $(\mathrm{H} / \mathrm{Z})$ pertencentes ao sistema de produção de leite da Fazenda Experimental da Empresa de Pesquisa Agropecuária de Minas Gerais (EPAMIG), no município de Felixlândia, Minas Gerais, no período compreendido de janeiro de 2002 a dezembro de 2010.

O rebanho bovino era composto por 200 fêmeas $F 1 \mathrm{HZ}$ que envolvem os cruzamentos: Holandês x Gir, Holandês x Guzerá, Holandês $x$ Nelore e Holandês $x$

Azebuado. Este último constituído basicamente de vacas indubrasiladas ou giradas, ou seja, vacas sem um padrão racial definido, mas com $100 \%$ de sangue zebuíno. Parte do rebanho foi adquirida de produtores mineiros de fêmeas meio sangue, em diversas regiões do estado.

As vacas foram mantidas em pastagens com as gramíneas Brachiaria decumbens e Brachiaria brizantha durante a estação das chuvas, época em que todo rebanho foi mantido em pastagens. Na estação da seca, as vacas em lactação receberam suplementação volumosa à base de silagem de milho ou cana-de-açúcar de acordo com o período de lactação. O fornecimento de concentrado ocorreu baseado na produção leiteira e período da lactação conforme descrito por Ferreira et al. (2010).

Os pesos coletados foram aqueles ao parto e a cada 28 dias até o próximo parto. Para caracterizar a variação do peso de vacas F1 de diferentes composições genéticas, as avaliações foram feitas por grupo genético e por ordem de parto.

Para descrever a variação do peso ao longo da ordem de parto, foi feito teste de regressão e selecionado o modelo que mais se ajustou (linear ou quadrático). Para o processamento das análises estatísticas, utilizou-se o software Sistema de Análises Estatísticas (SAEG 9.1).

\section{Resultado e discussão}

O grupo genético Holandês x Gir apresentou comportamento quadrático para variação de peso na primeira ordem de parto, diferenciando dos demais grupos (Figura 1), que mantiveram o peso durante todo o período pós-parto. As vacas F1 Holandês x Gir, perderam peso no início da lactação, possivelmente pela maior produção na fase inicial da lactação. Se considerarmos que a vaca $\mathrm{F} 1$ holandês $x$ Gir, é formada a partir de duas raças especializadas para leite, o que a torna mais exigente, associada à redução de consumo no início da lactação e ao estresse da primeira lactação, explica-se esta perda inicial de peso. Com o decorrer da lactação, aumenta-se a capacidade de consumo de alimentos e diminuem-se as exigências nutricionais pela redução da produção de leite na fase final da lactação, refletindo em ganho de peso nessa fase. Nas outras bases genéticas, proveniente do cruzamento de touros da raça holandesa, com matrizes zebuínas não selecionadas para leite, pode ter ocorrido atendimento das exigências pela dieta fornecida. De acordo com Santos et al., 2012, as recomendações do NRC (2001) não são as mais adequadas para esse genótipo, visto que, mesmo considerando um menor nível produtivo, esses animais não apresentaram variação do peso na fase inicial, caracterizado por perda de peso, o que é um comportamento padrão em vacas leiteiras especializadas.

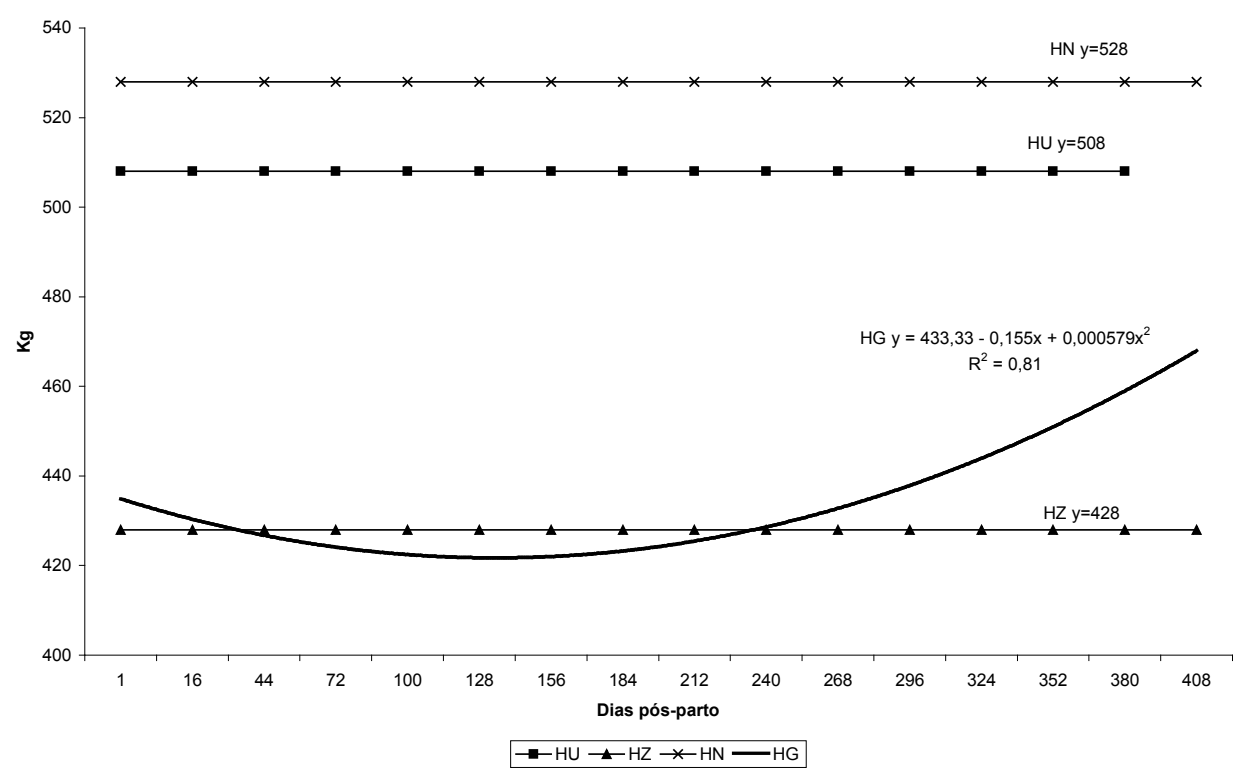

Figura 1: Curva de variação do peso de vacas $F 1$ Holandês $x$ Zebu na primeira ordem de parto: $H G=$ Holandês x Gir; HGU = Holandês x Guzerá; HZ = Holandês x Azebuado; HN = Holandês x Nelore.

Na segunda e terceira ordens de partos, apenas o grupo Holandês x Nelore não apresentou comportamento quadrático para variação de peso (Figuras 2 e 3). Este grupo genético apresentou aumento linear de peso no segundo período pósparto e na terceira ordem manteve o peso durante todo período pós-parto. Esses fatos podem estar relacionados com um desequilíbrio da dieta em relação à exigência do animal para produção de leite, tendo em vista que é um animal proveniente de cruzamento com raça de corte. Para os demais grupamentos genéticos o comportamento do peso após o segundo e terceiro partos foi o esperado, ou seja, perdeu peso no início da lactação e recuperou na fase final desta.

De acordo com Rennó et al. (2006), a produção de leite influencia diretamente as alterações metabólicas, taxa de lipólise e lipogênese bem como a partição de nutrientes. Essas 
alterações ocorrem em função da produção de leite influir diretamente na ingestão de alimento principalmente na fase inicial da lactação, intensificando ou não o balanço energético negativo, o qual é mais pronunciado em vacas de alta produção.
Esse comportamento também pode ser explicado por ainda não serem de total domínio os requerimentos nutricionais de vacas F1 Holandês x Zebu, sendo utilizados os requerimentos de vacas especializadas que são diferentes neste aspecto.

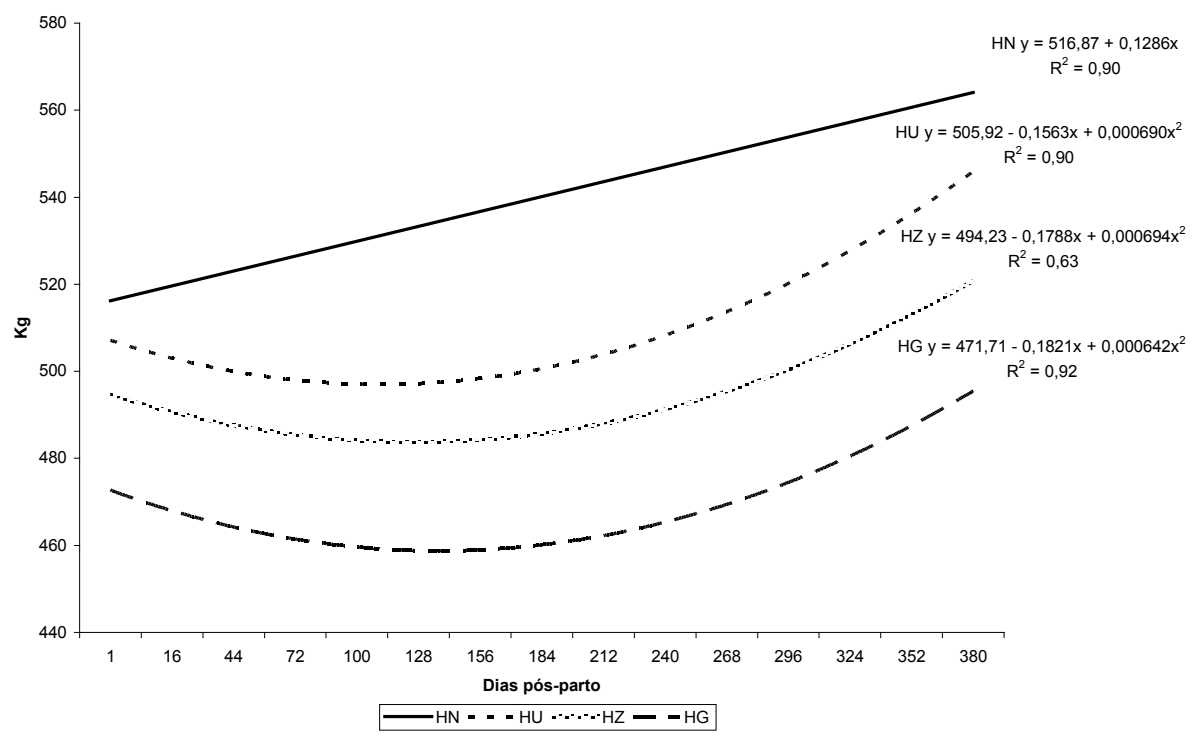

Figura 2: Curva de variação do peso de vacas $F 1$ Holandês $x$ Zebu na segunda ordem de parto: HG =Holandês x Gir; HGU = Holandês x Guzerá; HZ = Holandês x Azebuado; HN = Holandês x Nelore.

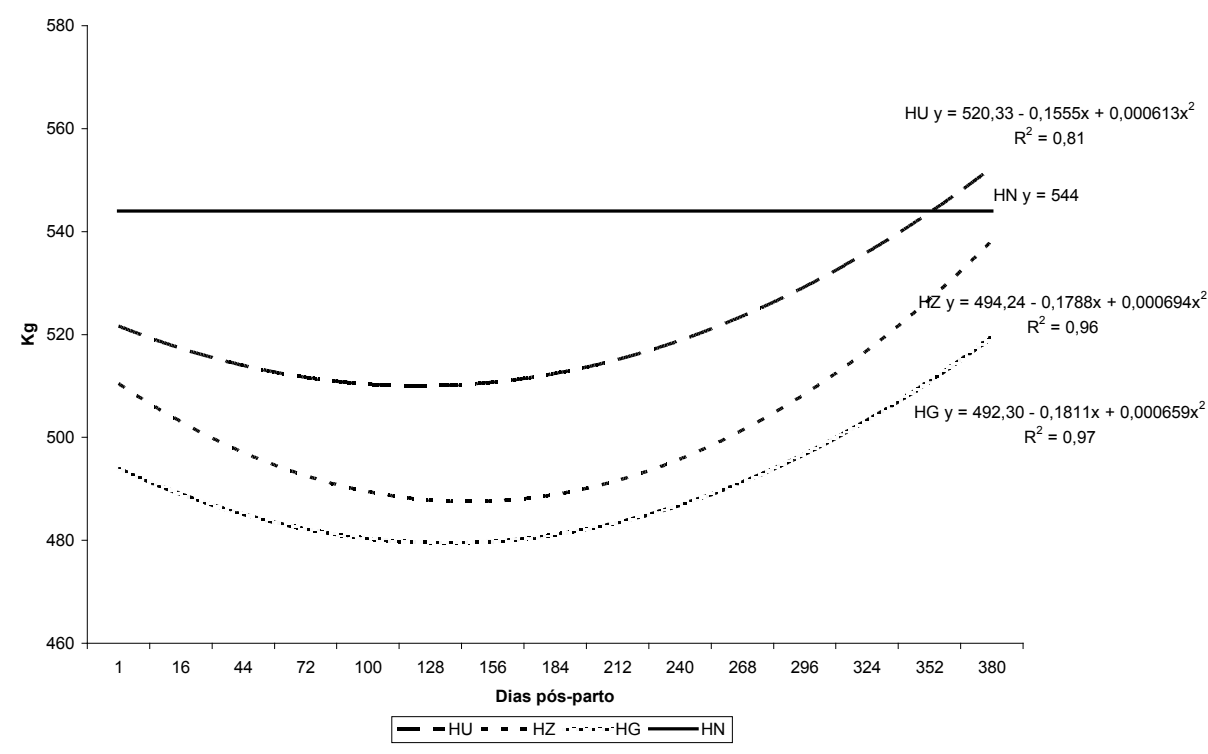

Figura 3: Curva de variação do peso de vacas F1 Holandês $x$ Zebu na terceira ordem de parto: HG =Holandês $x$ Gir; HGU = Holandês $\times$ Guzerá; HZ = Holandês $\times$ Azebuado; HN = Holandês $x$ Nelore.

Na quarta ordem de parto, o comportamento do peso foi quadrático em todas as bases (Figura 4). Entretanto, o ponto de máxima da equação para o grupamento genético Nelore foi positivo, demonstrando que este genótipo ganhou peso após o parto, o que pode ser atribuído à dieta que atendeu às exigências de produção de leite e ganho de peso, fato comum em gado de corte em condições de boa nutrição. 


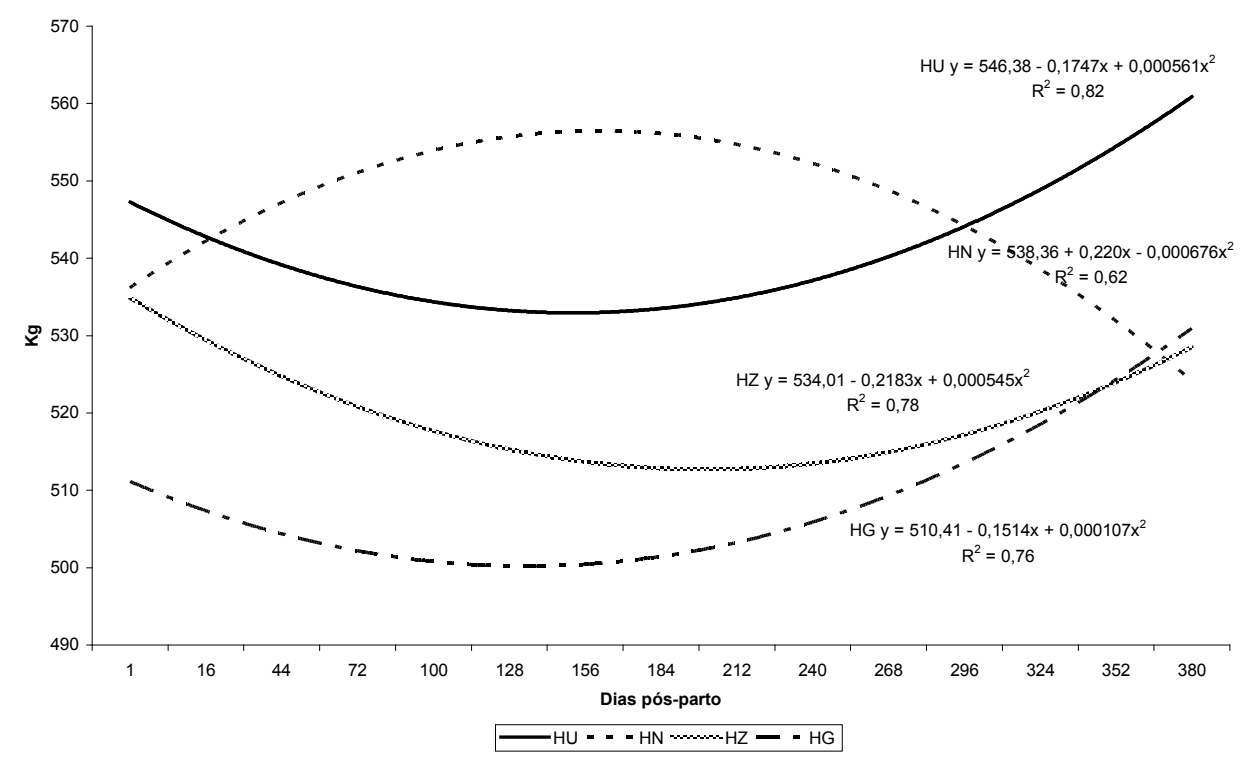

Figura 4: Curva de variação do peso de vacas $F 1$ Holandês $x$ Zebu na quarta ordem de parto: $H G=$ Holandês x Gir; HGU = Holandês x Guzerá; HA = Holandês x Azebuado; HN = Holandês x Nelore.

$\mathrm{Na}$ quinta ordem de parto, vacas F1 Holandês $\mathrm{x}$ Nelore apresentaram o mesmo comportamento da ordem anterior, ou seja, variação de peso semelhante animais selecionados para corte. O genótipo Holandês xAzebuado mostrou comportamento quadrático nas ordens 5 e 6 , com ponto de mínima, fato comum em gado selecionado para leite. Para os demais grupamentos genéticos não foi observado variação de peso nestas ordens. A falta de padrão na variação de peso de vacas F1, em parte pode ser atribuída ao não conhecimento das exigências nutricionais destes genótipos.

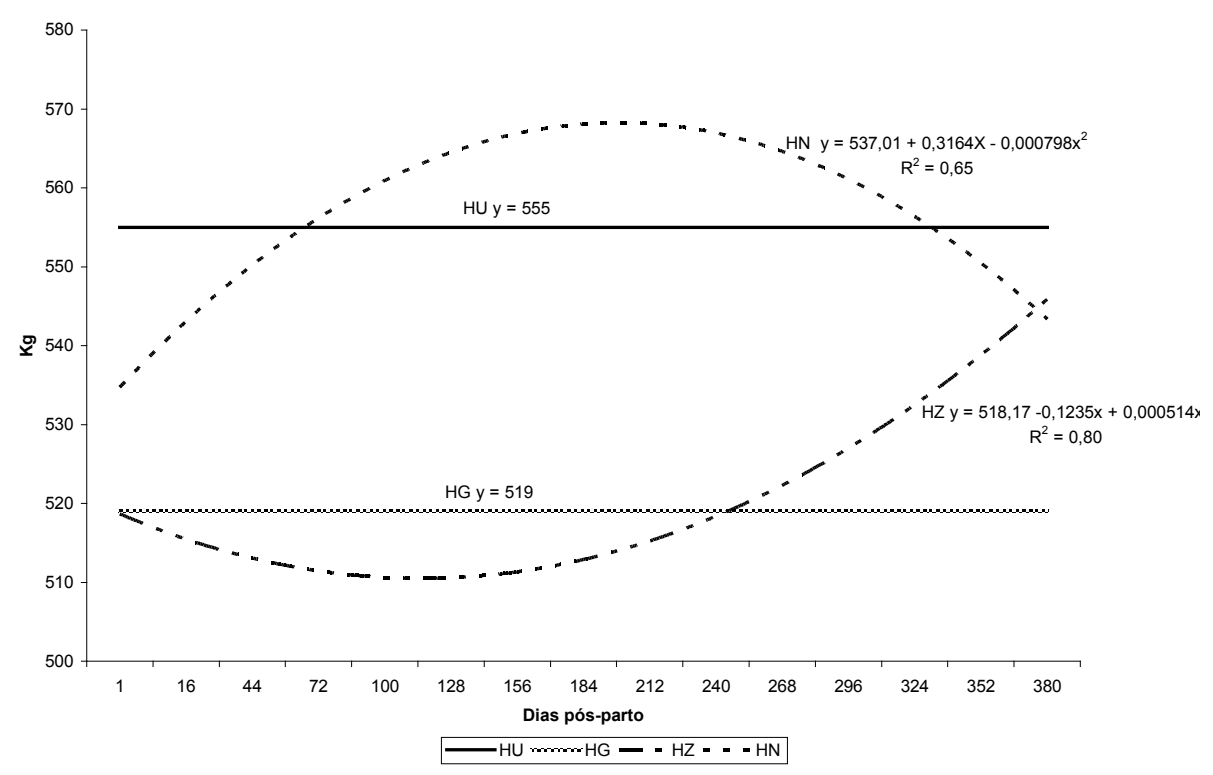

Figura 5: Curva de variação do peso de vacas $F 1$ Holandês $x$ Zebu na quinta ordem de parto: $H G=$ Holandês $x$ Gir; HGU = Holandês $x$ Guzerá; HZ = Holandês $x$ Azebuado; HN = Holandês $x$ Nelore. 
Confirmando esta variabilidade no peso após o parto, observou na sétima ordem de parto, que o grupo genético Holandês $x$ Gir apresentou comportamento quadrático, enquanto o grupo Holandês $x$ Azebuado linear crescente. Por outro lado, as bases Holandês x Guzerá e Holandês x Nelore não apresentaram variação de peso ao longo da ordem de parto (Figura 7). Essa diferença nos animais de base Nelore e Guzerá ocorreu possivelmente em função de apresentarem menor produção de leite e consequente menor exigência na fase inicial em relação às bases Gir e Azebuado.

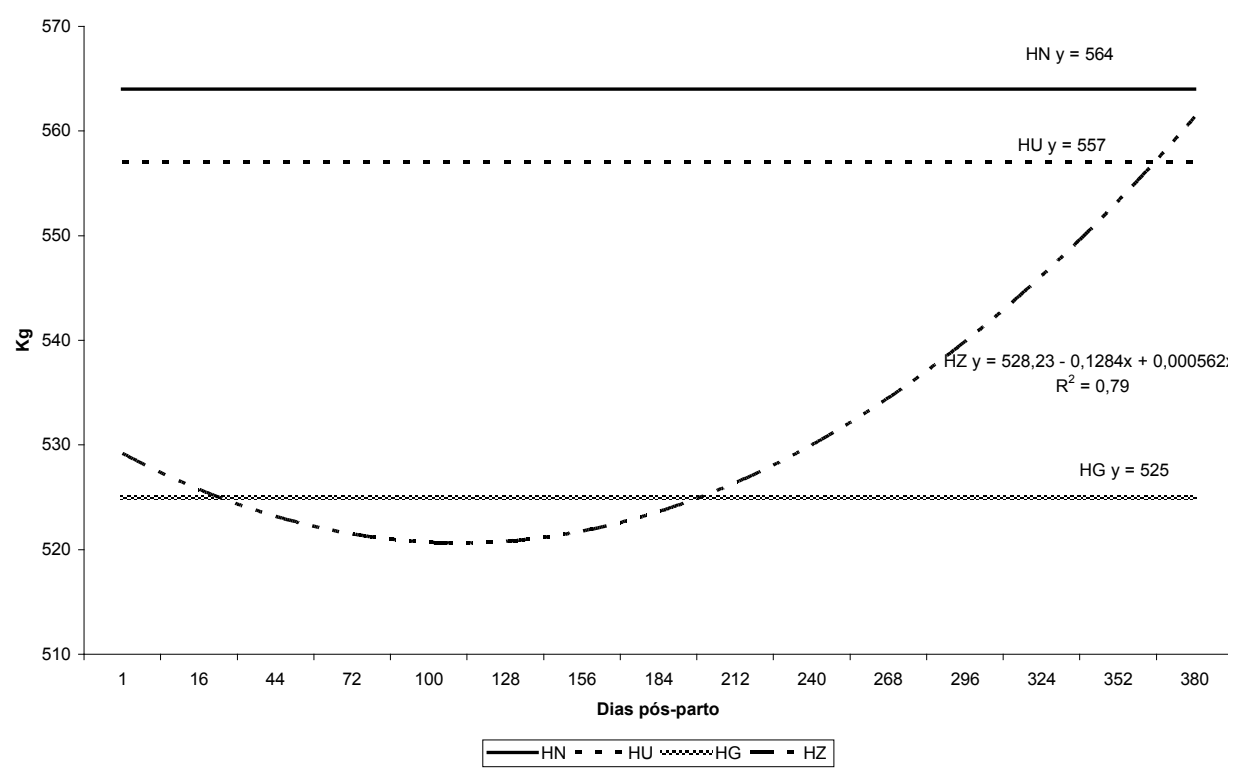

Figura 6: Curva de variação do peso de vacas F1 Holandês $x$ Zebu na sexta ordem de parto: HG =Holandês $\times$ Gir; HGU = Holandês x Guzerá; HZ = Holandês $x$ Azebuado; HN = Holandês x Nelore.

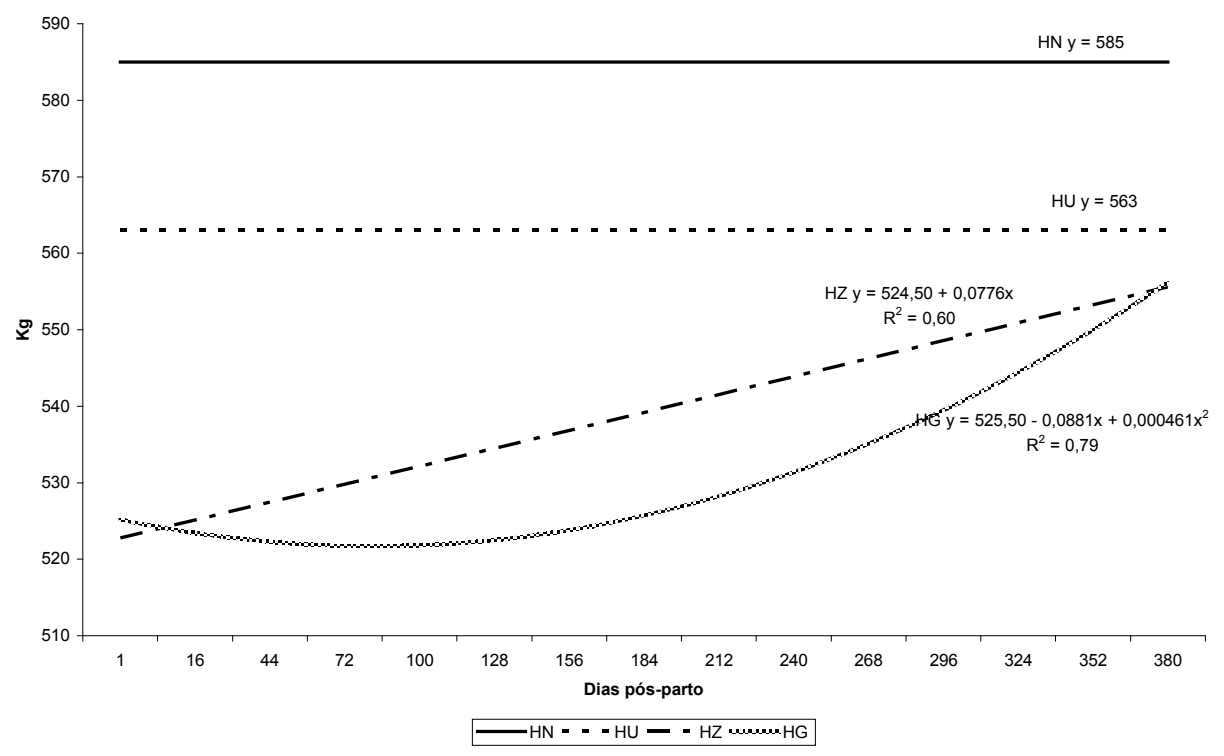

Figura 7: Curva de variação do peso de vacas F1 Holandês $x$ Zebu na sétima ordem de parto: $H G=$ Holandês x Gir; HGU = Holandês x Guzerá; HZ = Holandês x Azebuado; HN = Holandês x Nelore. 
Na oitava e nona ordens de partos, todos os grupos genéticos apresentaram peso constante ao longo da ordem de parto (Figura 8 e Figura 9), situação não comumente encontrada em vacas leiteiras, fato que pode ser atribuído a desajuste da dieta, devido à falta de estudos específicos dos requerimentos dietéticos de vacas mestiças F1 Holandês x Zebu.

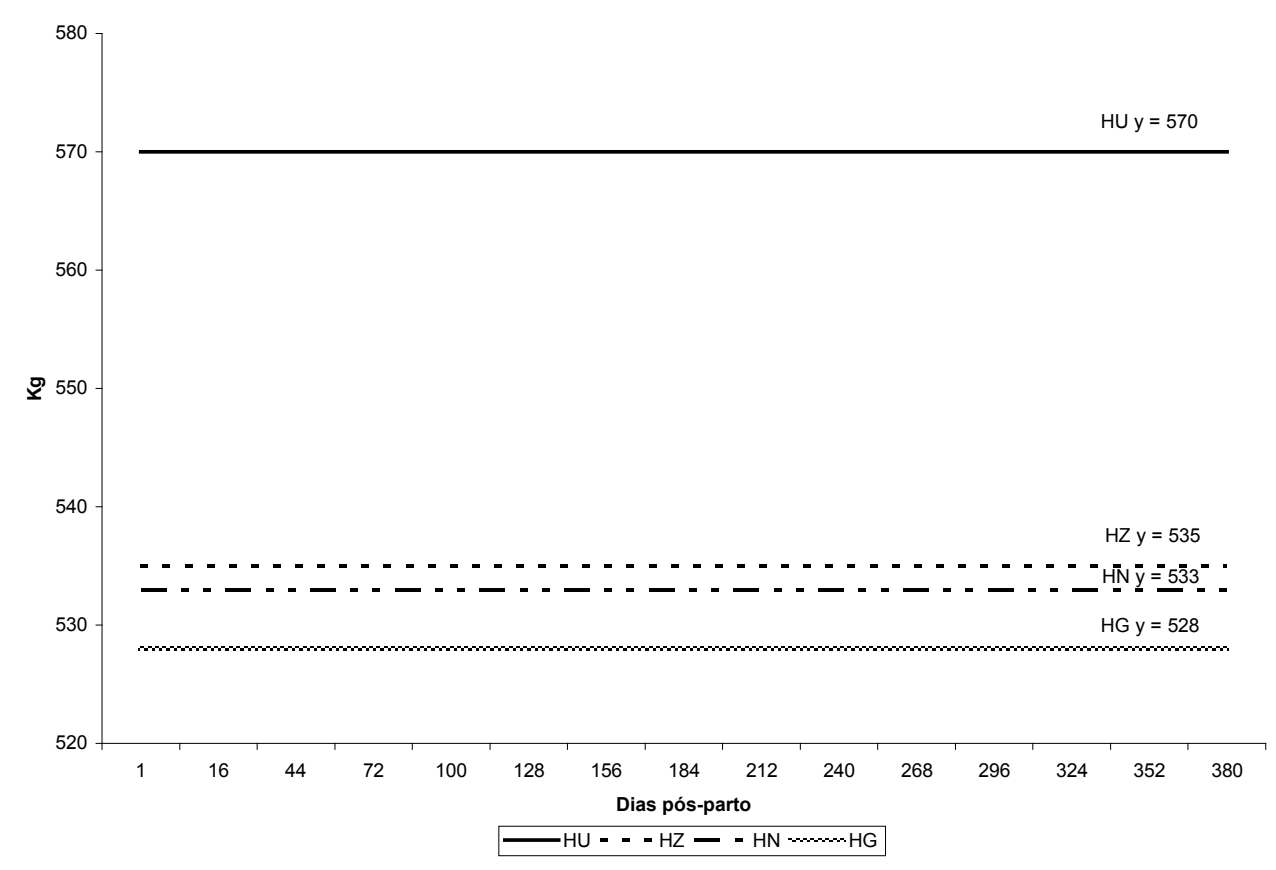

Figura 8: Curva de variação do peso de vacas F1 Holandês $x$ Zebu na oitava ordem de parto: $H G$ =Holandês $x$ Gir; HGU = Holandês x Guzerá; HZ = Holandês x Azebuado; $\mathrm{HN}=$ Holandês x Nelore.

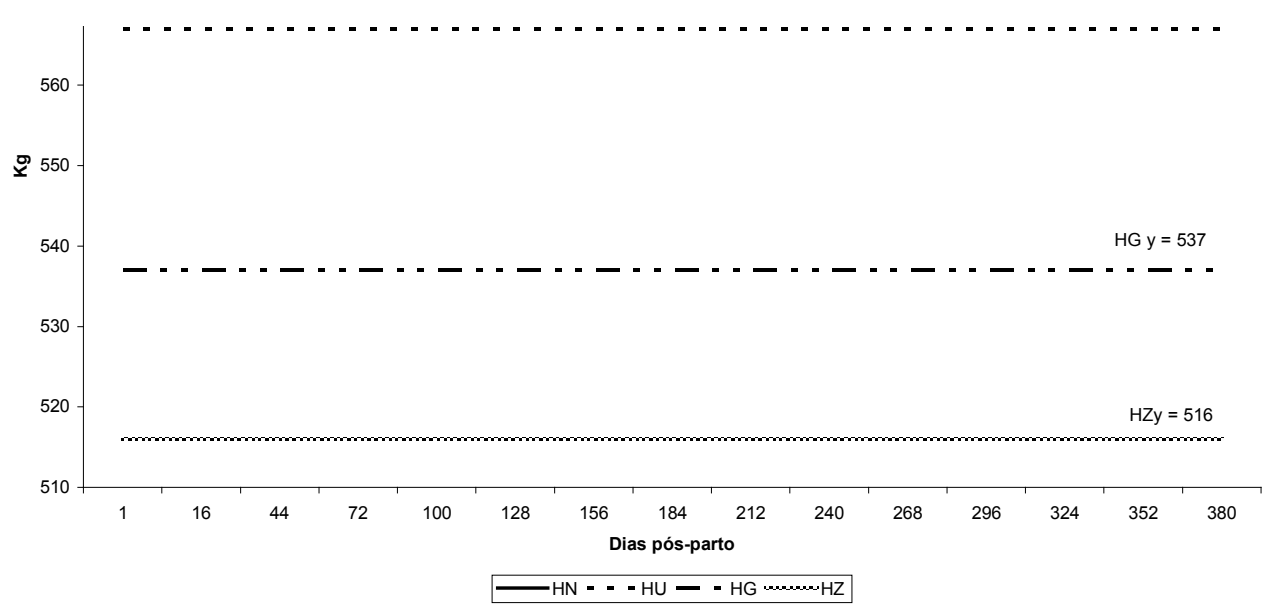

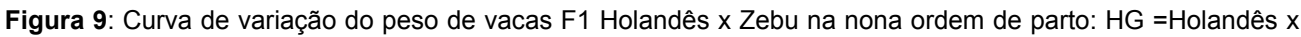
Gir; HGU = Holandês $x$ Guzerá; HZ = Holandês $\times$ Azebuado; $\mathrm{HN}=$ Holandês $\times$ Nelore.

\section{Conclusões}

A variação do peso ao longo da lactação, nas diversas ordens de partos e grupos genéticos, não apresentou o padrão mais comumente encontrado em vacas especializadas na produção de leite, o que indica um possível desajuste da dieta com as exigências requeridas. Em muitos momentos após o parto ocorre ganho de peso, sugerindo que o manejo alimentar utilizado não é o mais adequado, o que indica a necessidade de pesquisa na área de exigência nutricional de vacas cruzadas F1 Holandês x Zebu. 


\section{Agradecimentos}

Ao CNPq pelo apoio financeiro (Universal 472951/2011-4).

À Fapemig (PPM 0281/13, BIP 145/13).

Ao INCT-CA UFV.

À Epamig, Unimontes e Capes.

\section{Referências}

BUTLER, W.R. Produção de leite, balanço energético negativo e fertilidade em vacas leiteiras. In: XII CURSO NOVOS ENFOQUES NA PRODUÇÃO E REPRODUÇÃO DE BOVINOS. Anais... Uberlandia: Conapec Jr., p. 26-36, 2008.

CARVALHO, B. C.; RUAS, J. R. M.; SILVA FILHO, J. M.; FERREIRA, J. J.; SILVA, M. A.; MENEZES, G. C. C. . Avaliação de diferentes manejos pré-parto sobre o peso e o escore da condição corporal de vacas mestiças F1 Holandês x Zebu. Revista Brasileira de Ciência Veterinária, v. 16, p. 62-67, 2009.

FERREIRA J. J; RUAS, J. R. M.; CARVALHO, B. C.; SILVA, E. A.; QUEIROZ, D.S.; MENEZES, A. C. Alimentação do rebanho F1: fator de menor custo na produção de leite. Informe agropecuário: Vacas F1 Holandês x Zebu: produção eficiente de leite. v. 31, n. 258 , set./out. 2010
NRC-NATURAL RESEARCH COUNCIL. Nutrient requirements of dairy cattle. 7th. ed. Washinton, DC: National Academic, 2001. p.381.

PEREIRA, M. E. G. Produção de Leite em Diferentes Períodos da Lactação de Quatro Grupos Genéticos Meio Sangue Holandês X Zebu em Nove Ordens de Partos 2012. 78 p. Dissertação: Mestrado em Zootecnia Universidade Estadual de Montes Claros - Unimontes, Janaúba, 2012.

RENNÓ, F. P.; PEREIRA, J.C.; SANTOS, A.D.F.; ALVES, N.G.; TORRES, C.A.A.; RENNÓ, L.N.; BALBINOT, P.Z. Efeito da condição corporal ao parto sobre a produção e composição do leite, a curva de lactação e a mobilização de reservas corporais em vacas da raça Holandesa. Arquivo Brasileiro de Medicina Veterinária e Zootecnia, Belo Horizonte, v. 58, p. 220-233, 2006.

SANTOS, S. A.; VALADARES FILHO, S. C.; DETMANN, E.; Valadares, R. F. D. ; RUAS, J. R. M.; PRADOS, L. F.; AMARAL, P. M.; MARIZ, L. D. S. Intake, digestibility and nitrogen use efficiency in crossbred F1 Holstein Zebu grazing cows. Revista Brasileira de Zootecnia (Online), v. 41, p. 1025-1034, 2012. 